\title{
STUDIES IN THE MARKET SPONGES I. GROWTH FROM THE PLANTED CUTTING
}

\author{
By L. R. Crawshay, M.A.
}

Lately Research Officer, Sponge Fishery Investigations

(Text-fig. I)

CONTENTS

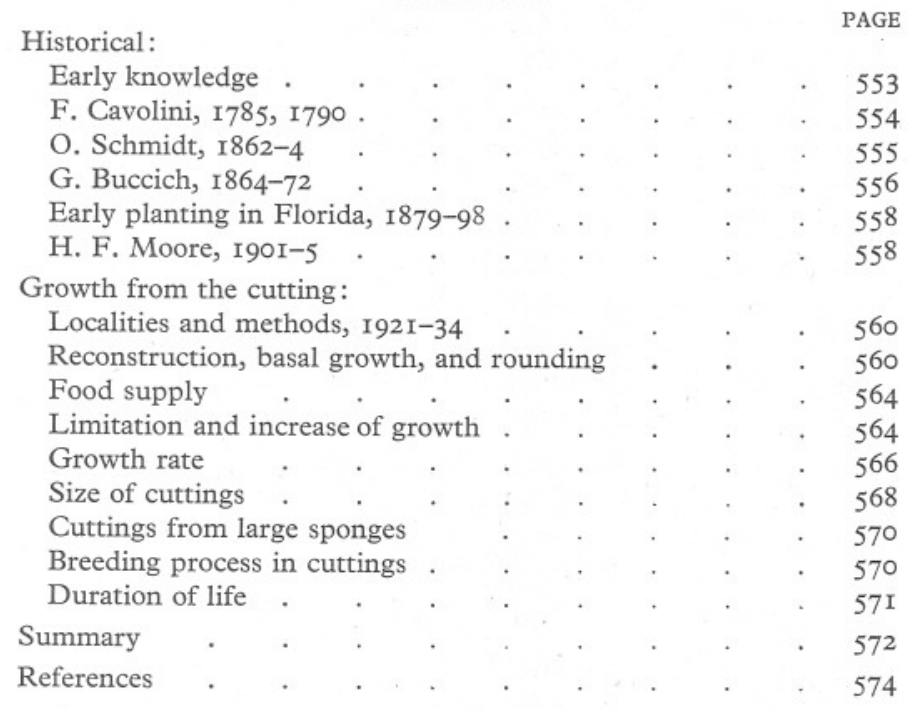

\section{HISTORICAL}

\section{EARLY KNOWLEDGE}

Reconstructive growth in sponges, in its broad sense at least, was probably well known to the early Greeks. A passage is quoted by Oscar Schmidt (I862) from a translated text of Aristotle's Historia, in which, referring especially to his second sponge, $\pi v \kappa \nu o ́ s$, the statement occurs: "Si autem abrumpantur, ex eo quod relictum est, renascuntur et complentur." This is omitted in D'Arcy Thompson's translation (I910), though in another place $(548 b$, I5) a revised passage appears in nearly similar words: "but, if the sponge be broken off, it grows again from the remaining stump and the place is soon as well covered as before". It is, in any case, scarcely credible that a fact so generally known to sponge fishermen of the present day as the repair and renewed growth of a sponge from its torn attached remnant was not similarly known to fishermen of the distant past. 


\section{F. Cavolini, I785, I790}

It remained for Cavolini (I785, I853), in the years 1785 and 1790 , first to throw important light on this subject, through a number of experiments made by him with living sponges. In these experiments, which he carried out in certain sea caves at Naples, Cavolini was not concerned with any general economic question, but primarily with confirming his belief in the animal nature of sponges, as against the assertion of a recent observer that they were vegetables. The question was especially concerned with contraction of sponges when touched in the sea, as observed by the ancients, apparently here referring to Aristotle (I9IO, $548 b$, IO), and as confirmed by statements of the divers. Of the three sponges named, as chiefly used by him, the "Spugna officinale del Linneo" may possibly have been a form of the $S$. mollissima of O. Schmidt, though this is doubtful; the "Spugna carnose" was certainly a Hircinian; of the third, the "Spugna detta alcionio foraminoso dall" Imperato", the identity is obscure.

Failure of preliminary rough tests with an iron hook, on sponges growing on the sea bottom, to show the distinct body contraction which he expected, led to his hooking them from the bottom, and redepositing them in the sea for observation. The receptacles which he used for this purpose were of red pottery; not, as stated by Marenzeller (I878), ordinary vessels, but small bells (campanelle) made of this substance, used by boys in their play and apparently similar in form to sheep bells. Inside these, suitably small sponges of $2-3$ in. in diameter were placed, pierced and threaded through with a piece of cord, the ends of which were secured through the two holes at the inner end of the bell, where the clapper (battoccio) is normally fastened. The bells with their contents were then lowered into the sea and left for different periods-at first for 12 days - after which, when again raised, it was found that besides healing of the torn surfaces the sponges had made spreading attachment to the face of the bells, and in one case the author states that two were so closely grown together that he could not separate them.

Of the later observations, extending from May to August I790, the ultimately published account (Cavolini, I853) is rather fragmentary and lacking in continuity, being mainly, as it seems, a collection of incomplete records made by Cavolini covering this period. In these experiments, sponges were also fastened externally to the bells, some being much incised, or completely cut asunder into as many as four pieces, though whether any were planted as separate fragments is not clearly recorded. The purpose of this cutting was, in fact, further to observe the process of repair, which had previously been noted in the healing of injuries caused by the hooks, and especially injury of the torn base of the sponge removed from its natural attachment; full evidence of this repair appearing in his results. A statement in the earlier memoir (Cavolini, I785), of the author's confirmation of the assertion by the ancients that the sponge uprooted from the rock repairs itself 
from the root that remains, is apparently a direct reference to the passage attributed to Aristotle by Schmidt (p. 553).

It should here be mentioned that a remark by Vosmaer (I887, p. 29), where alluding to Cavolini having maintained the animal nature of many sponges, "obwohl er meint, dass die von früheren Autoren ausgesprochene Ansicht in Betreff der Contractilität der Schwämme eine irrige sei", is incorrect. As in the care of his material, Cavolini's statements are often marked by extreme caution. But that his observations confirmed the presence of such contractility is made clear by him from an early point in his experiments; although the process is so slight and gradual that, like the movements of the hands of a clock, bodily contraction is not easy to discern. Similarly later: "Risulta da ciò che la spugna sia degli animali lo più semplice: giacchè il suo muscolare è come una cellulare diradata, come una gelatina; che anzi questa gelatina viene inceppata tra quello ramosissimo semicorneo scheletro: i suoi moti provenienti dalla sensazione, sono debolissimi, e siccome più diradato è questo muscolare, cosi il sentimento minora, come accade nel citato alcionio d'Imperato" (Cavolini, I785, p. 27I).

\section{O. SCHMIDT, I862-4}

About or shortly before the year I862, Oscar Schmidt first drew attention to the economic possibilities of sponge culture offered by the planting of cuttings in an article contributed by him to the Wiener Zeitung; as a result he was invited soon afterwards by the Austrian Government to undertake experiments in this direction with the assurance of all necessary assistance. Schmidt (I862, p. 22) had stated that it was "known" that if an entirely fresh sponge was cut into suitable small pieces, and if these were replaced in the sea, they would grow and develop to complete individuals; later alluding (Schmidt, I878, p. 534) to the experience of naturalists in this connexion, and especially of Lieberkühn. If he was aware of the work of Cavolini, he makes no direct allusion to it. Marenzeller (I878), in his later review of the experiments of Schmidt and Buccich, seems to infer that he was not aware of it, alluding only incidentally to Cavolini's observations in a footnote, and remarking that these had later fallen into oblivion. Had it been otherwise it would seem strange that Schmidt did not at the outset perceive in the simple device of Cavolini, or more particularly in his use of pottery, a more promising medium of attachment than that of wood, which was destined greatly to increase the difficulties encountered by him and by Buccich.

Schmidt's (I864) preliminary experiments were carried out in the spring of I863, at Zlarin, and in the Bay of Socolizza of Lesina Island, in the Adriatic. The selected sponges were small, namely, of $2-2 \frac{1}{2}$ in. in diameter, these being cut into from four to seven pieces. The fragments were then fastened by smal wooden pegs to the bottom of wooden cases bored, in the sides and cover, with numerous holes of $\frac{3}{4}-\mathrm{I}$ in. in diameter, and so that on a surface of $2 \mathrm{sq}$. $\mathrm{ft}$. 
from twelve to twenty such pieces were placed. Three such containers, with their cuttings, were then loaded with stones and sunk in the sea in a depth of 8-Io ft. Examination of the contents after 4 weeks showed that while some of the cuttings had suffered harm from deposited mud, most of them appeared to be in healthy condition. Later, however, at 3 months from planting conditions were found to be far otherwise, comparatively few of the cuttings surviving. Losses were largely attributed to accumulating mud, though at the same time much harm had been caused by interference with the experiments, and removal of the material by fishermen.

Prior to this, Schmidt had observed that certain details of method needed correction and improvement. A substitute, for example, was required for the closed cases which were detrimental. Change also was needed in the method of attachment of the cuttings to which injury had occurred in the region of the wooden pins. On the whole he was confident that the main project in view was economically practicable. He did not perceive that in cuttings of so small a size a great additional strain was placed on the material in any conditions not wholly favourable to healthy growth.

\section{G. BuCCICH, I864-72}

In May of the following year, 1864 , it seems that the charge of the work was passed over wholly to Gregor Buccich, a telegraph operator at Lesina, who received for some time an appropriation from the Ministry of Agriculture in Vienna, and continued the experiments for some 6 years or more, the station being finally closed in 1872 . Details of the work and its results are described by Marenzeller (1878), who had access to all official reports, including especially that of Buccich on the whole subject, which forms the basis of Marenzeller's account.

From the latter it appears that the work was seriously obstructed throughout by continued disturbance, both accidentally and often intentionally, on the part of the local fishermen, and through a generally hostile attitude towards such innovations; and, in spite of the repeated protests made by Buccich, its continuance became, through this cause, impossible. In a brief allusion to the circumstances by Schmidt himself (1878, p. 535), shortly before the publication of Marenzeller's report, ultimate failure of the experiments was attributed to this cause, and secondarily to the destruction by Teredo of the woodwork employed. Apart from these facts he expressed no doubt concerning the satisfactory progress of the material itself, nor did he change his views regarding the economic possibilities of the general project.

Buccich's methods seem to have varied comparatively little from those previously used by Schmidt. Perforated wooden containers, in one form or another, continued to be used, the cuttings being fastened by wooden pins, which were ultimately secured in lengths of bamboo fixed in the containers. The latter were then ballasted with stones, and sunk to a depth of 5-7 m. 
Alternatively, fastening of the cuttings directly to flagstones was tried, but later abandoned through harmful results, attributed to accumulations of bottom deposit. Here also, as elsewhere, allusion is made to the supposed harmful effects of direct light on the cuttings. This has at no time been borne out within my personal experience, even in the full tropical sunlight of the West Indies, or in a small number of cuttings, planted in about 5 fathoms, and observed for a few weeks, during a stay in Cyprus in I929.

Sponges collected preparatory to planting were fastened inside a sort of fish carrier; and were later cut, with the minimum of delay, to a size stated as about $26 \mathrm{~mm}$. square. They were thus presumably about I cu. in. in volume, and nearly the same size as in Schmidt's first experiments. It will later be shown that a cubic inch would represent about one-tenth part only of the approximate volume of the standard-sized cutting latterly adopted in the West Indian planting.

Details of growth and general progress, obtainable from the report, are very limited, and especially, as stated by Marenzeller, owing to the disturbance of any continued observations. If the statement of Buccich, that in the first year a cutting grew to two or three times its original size, had reference to volume, this would represent a fair to good rate of progress. That he should have found, as stated, less growth in the second and third years than in the first and fourth years, is well conceivable only if in the middle period a comparatively reduced food supply occurred, as in some years may happen, and perhaps through exceptional shortage in rainfall.

The estimate by Buccich, of 7 years as the approximate period required for a cutting to reach marketable size, does not necessarily indicate a slow rate of growth, but is consistent with the very small size of the cuttings as planted. From Schmidt's own more definite statements concerning the size of sponges used, and the number of cuttings made from them, the average cutting volume appears as about $I \cdot I$ cu. in. Regarding this as equivalent to a sphere of $I \cdot 28$ in. in diameter, and, as against the "two or three times" increase in the first year, allowing an average annual volume growth factor of 2.0 for the whole period, in 7 years an average diameter of about 6.5 in. would be attained-or, in the more probable depressed form, a horizontal diameter exceeding this-which might reasonably be regarded as of "marketable" size. Had the cuttings been even six times the estimated volume, which again would be much below the optimum, they would have been capable, with the same average annual factor of 2.0 , of reaching the same size of 6.5 in. in average diameter in about $4 \cdot 4$ years.

The division of sponges into very small cuttings (prompted mainly, no doubt, by the mistaken idea of economy) has been an almost invariable tendency at the outset of planting and has certainly been one of the chief factors which have retarded progress in sponge culture. There seems, however, in the present experiments, to have been much lack of discretion in the handling of the sponges between collection and planting. Reference is made to the 
length of time during which sponges may with safety be left out of water, or on dry land, in winter and in summer, the time sometimes extending to hours. If, as too probably, this means that such unnecessary exposure of the sponges was often allowed to occur, there can be no doubt that much of the material must have suffered harm. Eighty years previously, Cavolini had followed the extreme and safer course of not allowing his sponges to pass through the air at all.

\section{Early Planting in FloRida, I879-98}

After the experiments at Lesina, certain attempts at economic sponge culture were made on the coast of Florida, and the results are referred to by Rathbun (1887) and more especially by Moore (1908). These were, first a small experiment in about 1879 by Fogarty, a buyer in Key West, with cuttings attached to stakes and wires; which was not carried to a conclusion. Later, and for some years following, Monroe experimented at Biscayne Bay with cuttings fastened to staves, stakes, etc., but without any definite success. In a more extensive experiment, about I897-8 by Dr Harris at Sugar Loaf Key, with some thousands of cuttings attached to galvanized wire, corrosion and breaking of the wire led to detachment and loss of the sponges with high mortality. None of these experiments yielded any serviceable data.

\section{H. F. MOORE, I9OI-5}

Dr H. F. Moore was commissioned by the U.S. Bureau of Fisheries in I90I to carry out experiments in different methods of improving the Florida fishery, and his results concerning sponge culture, extending over about 4 years, are fully described in his report (I908). Here it is only necessary to mention certain points in his work, which resulted in a very great advance in our knowledge of the subject. In methods chiefly needing attention for successful planting, a question of primary importance was the selection of a suitable medium of attachment for the planted cuttings. Ultimately, after many trials of different substances and in different forms, Moore was led to adopt the concrete disc, which, except for reduction of the original size, about Io in. in diameter, and perhaps some modification in form, is unlikely to be surpassed for practical purposes.

For attachment to the disc, except when a short wire spindle vertically piercing the cutting was used, a piece of small-gauge aluminium wire was passed through the cutting and through a hole in the disc on either side of it, the ends being twisted together below. In this manner the cutting was secured in position until able to form its own attachment to the disc. The size of the cuttings planted was at first small; subsequently, however, it was increased to about $\mathrm{I} \frac{1}{2}$ by $2 \frac{1}{2}$ by 3 in., or with a volume stated to be about $8-\mathrm{IO} \mathrm{cu}$. in., the latter being roughly the same as that adopted for cuttings in the West Indian experiments. 
Rate of growth in the planted cuttings was found to vary appreciably in different localities. The exact details are somewhat difficult to interpret, owing to the fact that Moore expresses growth mainly in terms of an annual increase of diameter, quoted as a single quantity only. If, as is to be presumed, this was an average of three dimensions, any such increase in a massive sponge must necessarily depend much on the volume of the latter, and itself increase annually with regular growth. In two grounds selected for comparison, Sugar Loaf Sound and Anclote Key, this annual diameter increase was found to be about $0.8 \mathrm{in}$. in the former, and about $\mathrm{I}$ in. in the latter. It was accordingly deduced that growth was slower in the one locality than in the other, and Moore was led to infer that at Sugar Loaf Sound the observations indicated the presence of a dwarfed stock of slower growth. He thought that this dwarfing resulted from the intensive fishing in the shallow and more accessible waters of the Sound and from the constant removal of the larger sponges. It is conceivable that in the course of time such a result might ultimately come to pass; but it is difficult to believe that it could happen in the comparatively short period of some 50 years, since the Florida fishery first attracted commercial interest, i.e. about I852 (Rathbun, I887, p. 830).

The observed growth rates are, however, shown graphically in a series of curves for each of the two grounds in question, indicating the volume increase recorded periodically for different series of cuttings. Examination of these curves does not clearly bear out the conclusion that there is an appréciable difference in growth rate on the two grounds. While for Sugar Loaf Sound a factor as low as 1.76 for increase in volume occurs for one short-period series covering 12 months, the average annual factor for the three series together amounts to I.99. As against this, the corresponding three series for Anclote Key, though more nearly uniform with factors between 2.03 and $2 \cdot 16$, show an average of 2.I I. Also, as between the two long-period series, covering 2.9 years for Sugar Loaf Sound, and 4.0 years for Anklote Key, the difference in average for the whole period is again comparatively slight, the figures being I.99 (the same as the average for this ground) and $2 \cdot 16$, respectively. It may here be mentioned that in the light of the West Indian observations an annual growth factor of 2.0 is generally to be regarded as a fair rate, though not a high one; if maintained from year to year it gives no cause to doubt the generally healthy progress of the growing material.

Moore concluded that a greater aggregate volume is ultimately attained by a greater number of cuttings: or as definitely suggested, by fifty as against twenty cuttings made from the same sponge. It is possible that this view was reached owing to the inadequate data available during the limited period of his observations; and it may also be due to incompleteness of results, through interference with the experiments, of which he complains, and other causes of material loss. Within my personal experience there is no evidence to support this view, for, assuming uniformly favourable conditions for growth, the rate of volume increase, though varying between different individual 
sponges, is approximately the same for a large cutting as for a small one, made from the same sponge. Apart from positively adverse conditions decrease in the growth factor only appears with approach in size to the maximum volume which the feeding capacity of the sponge can sustain, and this again varies much between different individuals.

\section{GROWTH FROM THE CUTTING}

\section{LOCALITIES AND MeTHODS, I92I-34}

This section of the paper, concerning the general subject of growth from the cutting, is based on observations and experience acquired during the course of the Sponge Fishery Investigations, which were carried out on behalf of the Colonial Office and extended over several years. The data were largely obtained on the coastal grounds of the Island of Abaco, in the northern part of the Bahamas, between the years I92I and I928; but included also are the results of numerous planting experiments carried out in the Lagoon of Turneffe, British Honduras, between 1926 and 1934.

In the Bahamas, sponges collected from different and often distant grounds were carried in boats fitted with flooded wells kept in communication with the sea, and thus conveyed to the experimental depot ground, closely adjacent to the Laboratory, where they were deposited, either for observation as complete sponges, or for subsequent division into cuttings. In British Honduras similar methods were followed, but as the station was located on a reef it had not the facilities of an adjacent depot; observation of the material was made by periodic visits to the different planting centres, extending over a large area within the lagoon, from within which all sponges were obtained.

For purposes of basal support, concrete discs were used throughout from an early date. The size of these ranged from $3 \frac{1}{2}$ to $\mathrm{Io}$ in. in diameter; the latter was used infrequently and for special purposes only, the disc chiefly used during the later part of the work being $4 \frac{1}{2}$ in. in diameter at the upper surface. Except in certain grouping experiments, all discs were numbered by means of a series of short cuts made with a hacksaw, proceeding from a zero point on the upper surface and arranged on a decimal system around the different faces and edges of the disc. These marks were thus indelible; they could be extended to high numbers and with their help the progress of the cutting could be recorded over an indefinite period.

\section{Reconstruction, Basal Growth and Rounding}

Assuming the presence of favourable conditions of location and the important essential of careful handling of the material, fragmentation, carried out by the clean cutting of a market sponge, is followed in a very short period, commencing almost at once, by a lengthy process of general reconstruction, 
as required to equip the cutting for independent existence and self-maintenance. If all things are favourable the loss in volume directly due to cutting is, or should be, practically negligible.

It may be noted here that a normal and healthy sponge has certain requirements in which a cutting is at first partially or wholly deficient. These include the complete investment of the whole outer surface with a covering pellicle, accompanied in parts, where much exposed to the sunlight, by a protecting zone of densely pigmented cells, and normally - though not strictly essentialsome basis of attachment. In addition the canal system contained within the severed fragment must be modified to suit the sponge to a separate existence.

Though a cutting may be orientated in any position, and, as mentioned by Moore, successful growth may be effected by a fragment from the interior of the sponge without any part of the dermal surface, absence of the latter is liable at least to retard progress in early growth, if not to give occasion to higher mortality. On this point the results of the experiments have led to the conclusion that the optimum conditions in planting are provided by retaining in the fragment a portion of the original dermal surface, and securing the latter downwards, against the concrete planting disc, or other base of attachment. It follows therefore that, in this position, the change involves considerable readjustment of the canal system, for the surviving remnant of the porebearing surface has now to be closed off to form the attaching base of the new sponge.

In the newly cut fragment (Fig. I) it is questionable whether any one or other of these processes has a prior call. All appear to proceed simultaneously. Healing-the formation of a delicate covering on the cut surfaces-is a matter of a few hours only. Concurrently with this, closure of the larger surface apertures-no longer to function as previously, or only very partially so, in the new canal system-is more gradual, and in accordance with their size may occupy a day or two for purposes of preliminary completion. In this the process appears to be much more a matter of upgrowth and closing from within and below than of covering in at the extreme surface. The importance of this is evident in cases of local subsurface injury, where, if the injured part becomes enclosed within the body of the sponge, need may arise for the complete walling off of an interior damaged and macerating region. Such a space, especially if large, is liable not to be reoccupied, but to remain a closed cavity containing at length only the remnants of the dead skeleton. Otherwise, if close to the surface, the injured region will in due course be sloughed off, and the space will probably be refilled ultimately by new growth from below.

Simultaneously with the new dermal covering a varying number of quite small apertures are left unclosed to form the new oscula.

The number of these, though variable and differing with the characters of the sponge, is usually very small; and in small cuttings at least there may at first be no more than one. The position is also very variable, and probably determined by that point of the new surface where a section of the existing 
canal system provides the most complete and effective means of communication with the remainder in the adjustment of the new system of circulation. Commonly, around each of these early oscula, a delicate tubular outgrowth is soon extended, and very shortly a strongly working circulation is restored.

Concurrently with this change, pigmentation of the newly cut surfaces proceeds by gradual stages; and if light conditions are strong, becomes appreciably visible to the eye within a few hours. Complete "blackening" of the surface, which is a matter of degree in the massing of increasing numbers of deep brown pigmented cells at and below it, is more gradual, and may

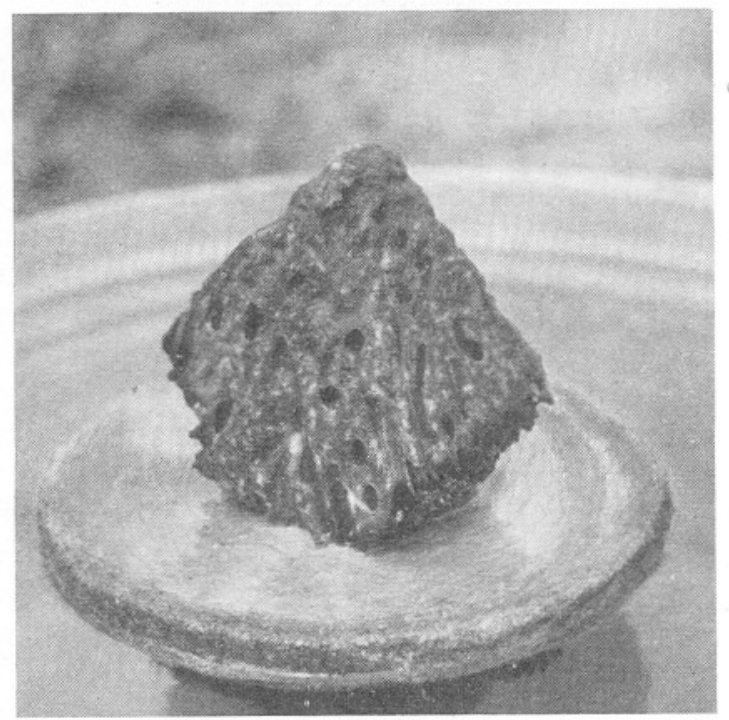

Fig. I. Newly made cutting from a Wool sponge. The disc is 7 in. in diameter.

occupy a week or two, depending on the intensity of the sunlight. Where screened from the sun, as in certain lower parts of the subsequently growing sponge, pigmentation is much reduced or wholly absent.

Progress in growth and change is necessarily very variable, depending on food supply and other conditions. Where a fixed base of attachment is present, as provided by the concrete disc to which the cutting is firmly secured (see Fig. I), downward growth from the lower region of the cutting is a prominent feature from an early period; and continues until complete attachment to the disc is effected by the sponge itself. This process is gradual, and may occupy a period ranging from a few weeks to a few months, depending much on circumstances of location. If the position is disturbed, or the cutting insecurely fastened at the outset, attachment may never occur, the base then becoming merely rounded off and strengthened against friction by additional fibres. It should here be explained that it has been customary of late years for certain 
planters to follow the method adopted by Moore of fastening the cutting by a length of aluminium wire passed through it, and through a hole in the disc. The method adopted in all planting experiments here described has, however, been to secure the cutting firmly by means of a pin, passing through both cutting and disc. This pin is made from the thoroughly dried stalk of palmetto, with a small projecting head at the upper end to prevent lifting of the cutting.

When the basal attachment is completed it is usually followed by a more or less pronounced extension of the base as a thin marginal plate, and it is probable that this process has as much importance for feeding purposes in that region as for general attachment.* After a time the basal marginal extension not infrequently reaches the edge of the planting disc; it will then often pass over the edge, and continue down the side until, with increasing growth, the whole of the disc except the lower surface may become enclosed within the base of the sponge.

As previously stated, the rule adopted almost invariably, from an early period of the work, has been to plant the cutting with its portion of the dermal surface downwards and tangentially against the disc. The exact details of the fate of the original dermal covering of this part of the cutting have not been followed. It seems that, in a healthy sponge, it must be absorbed. In the ultimate basal growth there remains no visible trace of it as distinct from any other part of the original cut fragment, but in section it is usually distinguishable by its darker colour from the new growth around it. The ultimate investment of the disc, or other basis, by the cutting is so complete that in the grown sponge every detail of irregularity in the surface of the object is usually distinctly impressed on the base of the sponge and on the surface of its skeletal network after maceration.

On this subject of basal growth-perhaps more properly, in its origin at least, to be regarded as cell migration-some digression has been made from that of the general growth. Assuming that roundness is a character of the original sponge, a primary object in growth is to restore rotundity of form to a cutting which is at first roughly pyramidal (Fig. I). This restoration takes place through a gradually increasing convexity of the separate cut faces as a first step, with, later, complete obliteration of the original lines of the cutting. Progress in this direction will vary considerably with location: on grounds where food supply is abundant, and growth rapid, rotundity may be acquired in about 3 or 4 months; on other grounds it may take twice the time, or longer.

Roundness of form, however, in any strict sense of symmetry or regularity, is very far from being an invariable rule among the market sponges, or in any one species of them; and, though the question of form variability cannot

* It should perhaps be explained that this basal outgrowth is here regarded simply as an outward extension of the sponge body, and as functioning in continuity with it in all respects. Though not examined in detail, the conditions are apparently similar to those of corresponding basal outgrowths formed by certain Plymouth sponges, while kept under observation in the laboratory, as, for example, in Esperella. In these the canal system is continuous, with flagellated chambers extending almost to the extreme limits of the investment. 
conveniently be discussed here, it may be stated that where any marked irregularity of growth occurs in a sponge the features constituting such irregularity will usually be shown in the cutting made from it at an early stage of growth, and independently of roundness as a premier character.

\section{Food SUPPLY}

Rate of progress of a cutting must of necessity depend largely on food supply, the exact nature of which is uncertain. It may, however, be said that, speaking generally, most favourable conditions for growth are usually found in or near to positions subject to regular tidal interchange, combined with the presence of waste organic products carried down from land areas, or otherwise leading to deposits of partially organic mud. It is not improbable that part of the food is derived through ingestion of the finer particles of waste organic matter itself; but the fact that some of the most favourable situations are far removed from land, and chiefly characterized by heavy deposits of extremely fine calcareous mud-produced, as ascertained by Drew (I9I4), by denitrifying bacteria-suggests that certain bacteria form in themselves the chief source of supply.

Resting in, and largely covered by this mud, commonly at many miles from land, the sponges thrive and grow rapidly, attaining to the largest sizes reached in the Bahamas, and they often retain remarkable regularity and massiveness of form with their increasing growth. The intensity of the bacteria associated with this mud, chiefly B. calcis, is well shown in the fact that, at 3 miles out from the shore from the western end of the Southern Bight of Andros, Drew (1914, p. 42) estimated that there were 35,000 bacteria in each c.c. of surface water and $160,000,000$ per c.c. in surface samples of the mud. He notes that the last figure may be underestimated owing to settlement of bacteria during the preparation of his cultures.

\section{LIMITATION AND INCREASE OF GROWTH}

In the absence of directly unhealthy factors life may continue in the cutting, even for some years, under conditions of food-shortage; but growth is much retarded or absent, and there may be an actual decrease in the living volume. In such conditions the existing resources of the individual appear to be primarily employed for purposes of attachment, possibly including the quest for food supply through the medium of the basal extension (p. 563), and secondarily for gradual reconstruction of the natural form. In conditions of bare maintenance this may involve some withdrawal from parts of the outer and upper surface areas, ridges and other prominences especially being vacated, and the retraction at times extending over parts of the cut surface to a depth of perhaps $\frac{1}{2} \mathrm{~cm}$. or more. Here, the new surface seals itself over, and the vacated 
skeleton endings shortly die and, after a month or more, slough off, leaving the new dermal surface wholly bare. In extreme cases of serious partial injury, such as possibly occur through temporary conditions of pollution, so long as it does not extend to the entire cutting, an unharmed portion may still effect recovery by walling itself off from the remainder, and in due course forming a completely rounded and separate small unit, perhaps not exceeding about $2-3 \mathrm{~cm}$. in diameter.

In the normal course progress towards completion of the natural form of the original stock will continue, as stated, through rounding of the surface, with gradual obliteration of the original lines of the cutting, and (if rotundity is a character of the sponge) until complete rotundity is reached. The positions of the dominant oscula will, in the meanwhile, be adjusted to the form, and be mainly confined to the upper surface, though in some sponges these may be partly lateral. The attainment of this stage may be slow, extending over a year or more, or, on the other hand, it may occupy only a few months.

Examples in earlier experiments of completely formed small sponges of no more than 6 or $7 \mathrm{~cm}$. in diameter after some 3 to 4 years from planting, appeared at first to support a prior view that growth and the life period are limited by the age of the stock from which the cutting is made. Subsequent observations, however, have not borne out this view; and, as far as is yet known, the possibilities of growth are unlimited by the age factor alone. With the passage of years a sponge grows to exceed its optimum volume in relation to its individual feeding capacity, and the available food supply around it. As with increase in volume the food shortage becomes relatively greater, maintenance of the individual as a complete whole becomes more difficult, and repair of local injuries becomes less complete. Parasitism and overgrowth also cause increasing interference with ingoing currents and excretion; and while modification of form, in adaptation to need, or often partial withdrawal from outlying parts of the skeleton, may prolong life for several years, ultimate decline and death seems rather attributable to uncontrolled growth than directly to loss of cell vitality with age. This view is in general agreement with the conclusions of Bidder (1932) regarding growth and death in sponges of this group. *

Where conditions are favourable to steady growth, increase in the cutting may range from doubling to trebling its volume, or occasionally more, in the year. Speaking generally, though different species vary in this respect, an annual growth factor of less than 2 is rather low, and suggestive of some deficiency, not necessarily harmful; in the local conditions. A factor of 2 may be regarded as fair, or a fair average, while 2.5 indicates a good rate of growth, and from the point of view of the planter is perhaps the most reliable. Increase showing an annual factor of 3 or more is high, and usually concurrent with the presence of exceptional accumulations of waste matter, which may at any time lead to disturbance of healthy conditions and harmful results to the

\footnotetext{
* See also p. 572 .
} 
planted material. Conditions such as these may be quite favourable to sponges of investing or creeping habit, as among certain Halichondriae and others; they are, however, disadvantageous or even dangerous to the large and massive market species, easily leading to congestion of the canal system and interference with excretion, with possibly fatal results. If congestion is not extensive and amounts to no more than mechanical stoppage of the canals, it may be remedied by the sponge itself, through isolation and abandonment of the affected region which will later disintegrate and fall away. Two or three of the growing sponges from a series of cuttings in British Honduras were found to be partially dead 3 years after planting, and examination of the material showed that a large part of the incurrent canals, to a depth of 2-3 cm. below the surface, were closely choked with fine mud. It was accordingly decided to cut and replant most of the remaining members of the series, and, with few exceptions, growth in the new cuttings proceeded normally. It is to be observed that the usual method of planting, with the old dermal surface downwards, served in this case to promote recovery.

\section{Growth Rate}

For observations of growth rate, it is first to be considered that, with certain exceptions, the general form of most market sponges having any definite approach to symmetry, though occasionally spherical, more commonly approximates to that of a depressed spheroid. Hence, while making any necessary correction required in cases of irregularity, estimates of volume are best obtained by the formula

$$
V=\frac{4}{3} \pi a b^{2},
$$

where $b$ is half the mean of two horizontal diameters at right angles, and $a$ is half the height. From the volume thus obtained of a sponge before planting, the fractional average for each cutting at the time of planting is known; and while the size of the cut fragments must necessarily vary, and at times considerably so, for estimates of later growth the selection of about five or six of a planted series will usually suffice to give very nearly the true average rate of progress for the whole.

If $V=$ the initial volume at the time of planting, $x=$ the volume reached at a future date, $y=$ the annual factor of increase, then the ratio of increase $x / V$ for I year $=y$; for 2 years $=y^{2}$; and for $n$ years $=y^{n}$; and generally, for all values, $y^{n}=x / V$; or, $y=\sqrt[n]{x} x / V ; \log y=\frac{\log x / V}{n}$.

Frequently a value other than $y$ is required, as for example the period at which, with $V$ known and $y$ approximately known or assumed, a certain volume $x$ will be attained; or, in the inverse order, with a present volume regarded as $x$ known and $y$ assumed, the approximate age of the sponge is required. As with the growth factor $y, n$ almost invariably involves a fraction, 
its exact or approximate value being obtainable through transposition of the last formula.

Estimates of progress in terms of the diameter were not ordinarily used for purposes of the experiments. If so required, and taking here, in each case, the average of three dimensions, if $d=$ the original average diameter of a sponge, $D=$ its increased average diameter, $p=$ the annual factor of increase in the average diameter, then similarly, as in the preceding formula for volumes: $p^{n}=D / d$; or $p=\sqrt[n]{ } D / d$, for any value concerned.

And since $p$ is equivalent to the cube root of the volume factor $y$; if, for example, the latter is $2 \cdot 0$, and sustained for the period, the average diameter of a sponge will thus be doubled in 3 years. Manifestly this cannot continue for very many years; and herein a striking aspect of sponge growth appears, in the capacity at once to resume such rate of increase as here considered, or a higher one, in a fragment severed from a sponge in which any volume increase may have long since ceased.

Actually, the growth rate of a sponge in a given location has been found to vary appreciably over different periods, and short-period observations may at times be misleading. In an early Abaco experiment (E. 6, Velvet), for example, data for the first 8 months were unobtainable through omission to measure the original sponge. For subsequent periods the following estimates of volume increase were obtained for the average of eight cuttings:

$\begin{array}{lcccc}\text { Feb. to Jan. } & \text { I0.9 months } & \text { Equivalent annual factor } & 2.24 \\ \text { Jan. to Dec. } & \text { II } .7 \text { months } & \text { " } & 2.30 \\ \text { Dec. to Aug. } & 7.5 \text { months } & \text { " } & 2.67 \\ \text { Total period } & 2 \frac{1}{2} \text { years } & \text { Average annual factor } & 2.36\end{array}$

For a single cutting, the largest of the series, the increase through the total period showed a nearly similar average annual factor of 2.34 . In this, as in the preceding case, the average rate of increase is calculated direct between the original volume and that of the ultimate growth.

In the foregoing example, as was the custom at the period, the cuttings were very small, and though of unknown volume, certainly did not exceed $2.5 \mathrm{cu}$. in.

The following example may be given of the high growth rate often observed at Turneffe, British Honduras. Fifteen cuttings of a Wool sponge showed after $9 \frac{1}{2}$ months an average increase equivalent to an annual factor of 2.94 . This rate, however, was not maintained: one cutting, No. 5585, during the succeeding I9 months, May to December, gave an annual factor of 2.14 , while in another, No. 5590, for $20 \frac{1}{2}$ months, May to January, it was 2.08 . No. 5590 was later replanted as eighteen cuttings on a different and distant ground and three of these cuttings, which alone were measured, gave after I $8 \frac{1}{2}$ months an average annual growth factor of 3.13 . If now the average ultimate volume of these three cuttings-nearly $69 \mathrm{cu}$. in.- - be compared with a similar eighteenth fractional part of the original average cutting at the first subdivision, i.e. I.02 cu. in., it is seen that the average annual factor for the 
whole period, 4.04 years, from July I926 to August I930, is 2.84 , or not far short of that found for the whole series at $9 \frac{1}{2}$ months. The two grounds are not quite similar, but the example illustrates the potentially high growth factor of the sponge in question, at the commencement of life as a cutting.

Variability in growth rate among different cuttings of the same sponge is necessarily more pronounced where the general growth factor is high. Though probably due to different causes, there is little doubt that it is largely attributable to the different regions of the sponge from which the cuttings were made, and especially as between the base and the upper and distal parts. In the cutting of a sponge, with comparatively rare exceptions, the general aim has been to replant the whole of the sponge, and in so doing to ensure as far as possible uniformity of size in the cuttings. The method employed is first to divide the sponge vertically into nearly equal complete segments, as many as its size allows; then to subdivide each segment transversely or obliquely to the original "polar" axis of the sponge. In the result it follows that certain cuttings are wholly basal, as contrasted with others from the extreme upper region; and it seems that the stronger growth occurs from the former. Though definite data are very incomplete, this view is supported by certain records of distinctly stronger growth in known basal cuttings. Further, in the few cases observed, it is in the lower region of a young sponge that the reproductive bodies first appear, presumably marking the zone of maximum vitality.

In conditions of food shortage growth may be much retarded or even suspended for a long period, but will again be resumed with change to a more favourable location. In an extreme case, in one of the Abaco experiments, a series of cuttings from a Wool sponge, planted in what proved to be an exceptionally unfavourable position, effected complete reconstruction as wellformed little sponges; but up to 30 months from planting no growth was made, and even a distinct reduction in volume had occurred. Survivors were then moved to another position some I50 yards away, in which after 7 months, when the material had to be removed, a pronounced change with renewed growth was observed, showing approximately the equivalent of an annual factor of $\mathrm{I} \cdot 7$ (though exact results were uncertain through incomplete data). In the second position, where many sponges were placed, the growth rate was usually low, rarely reaching an annual factor of $2 \cdot 0$.

\section{Size of Cuttings}

The number of cuttings that can be made economically from a sponge, and the size of the individual cutting, are questions of some importance. In similarly favourable conditions, though cuttings may vary to some extent between one another, small cuttings from the same sponge should make approximately the same rate of progress, in proportion to their volume, as large ones. But it is clearly advisable to observe some uniform standard of cutting volume, whether at all times to be closely adhered to or not, to be 
retained as an approximate basis of reference and comparison, for records of general progress.

During the latter part of the work such a standard was adopted in the form of a spheroid of 3 by 3 in. in horizontal diameter by 2 in. in height, showing an average diameter of 2.67 in. As sufficing for practical purposes, this was then treated as the diameter of a sphere, and was the unit employed in the preparation of a scale for general reference. The following table is given in illustration: the first column showing the number of cuttings to be made from a sponge of the diameter given in the second column.

\begin{tabular}{|c|c|c|c|}
\hline Cuttings & $\begin{array}{l}\text { Sponge } \\
\text { av. diam. } \\
\text { in. }\end{array}$ & Cuttings & $\begin{array}{l}\text { Sponge } \\
\text { av. diam. } \\
\text { in. }\end{array}$ \\
\hline I & $2 \cdot 7$ & 35 & $8 \cdot 7$ \\
\hline 2 & $3 \cdot 4$ & 40 & 9.I \\
\hline 3 & 3.8 & 45 & 9.5 \\
\hline 4 & $4 \cdot 2$ & 50 & 9.8 \\
\hline 5 & $4 \cdot 6$ & 55 & IO.I \\
\hline 6 & $4 \cdot 8$ & 60 & 10.4 \\
\hline 7 & $5 \cdot I$ & 65 & $10 \cdot 7$ \\
\hline 8 & $5 \cdot 3$ & 70 & II $\cdot 0$ \\
\hline 9 & 5.5 & 75 & II $\cdot 3$ \\
\hline Io & 5.7 & 80 & II. 5 \\
\hline 15 & $6 \cdot 6$ & 85 & II .7 \\
\hline 20 & $7 \cdot 2$ & 90 & 12.0 \\
\hline 25 & 7.8 & 95 & I2. 2 \\
\hline 30 & $8 \cdot 3$ & 100 & I 2.4 \\
\hline
\end{tabular}

In certain of the larger sponges, in which the depression of the spheroid may be considerable, an appreciable difference will occur between its average diameter and that of the sphere of equivalent volume. But, since the diameter of the sphere is the smaller, the result, if uncorrected, will only lead to a slight increase in the size of the cuttings above the standard, and this, on the whole, is preferable in the larger sponge.

It is difficult to cut a sponge at once into more than about sixty fragments without much distortion of the ideal and compact form, and this is liable to place undue strain on the material in its reconstructive growth. It is thus advisable first to cut sponges of large size into three or four large fragments, fastening them together with a piece of line; then later, after an interval of a week or two, when the cut surfaces have healed over, to carry out the complete subdivision. This will give greater scope for orientation of the cuttings, and they will be of a better shape, without having one of the newly cut surfaces resting beneath, which is not desirable.

As an example of steady growth, with exceptional uniformity of progress among the several cuttings and a rather high rate of increase over about $2 \frac{1}{2}$ years, through the first stage of cutting, mention may here be made of a Wool sponge planted at Turneffe in October 1927. A special point of interest is the exceptional regularity of the sponge itself, with almost perfect symmetry of form, and with its rather numerous cloacae regularly disposed over the upper surface. This sponge, H. 28I, had an average diameter of 9.5 in., and 
was divided into forty-three cuttings. The cuttings were therefore nearly to the standard scale (which would give 45), though made, as it happened, before any standard unit was adopted. In March I930, one only of the series was missing. The whole of the remainder had made nearly similar and regular growth, though slightly varying in size, and, for a fairly representative series of ten measured examples, the average annual factor, for 29 months, was found to be $2 \cdot 67$. There can be no doubt that the exceptional symmetry of form of the original sponge was largely accountable for the pronounced uniformity of growth and progress appearing in the whole planted series.

\section{CUTTINGS FROM LARGE SPONGES}

As bearing on the question of continued growth in cuttings made from a large sponge, the following example is deserving of record. At Turneffe there is a large-growing type of Velvet, of not infrequent occurrence, though regrettably now more scarce than in the past through lack of timely protection of the fishery. An example of this type, H. 38, was obtained in July 1926, having an average diameter of $16 \cdot 7$ in. During removal of the sponge to the planting ground a fragment of it, estimated at rather more than one-third, was carried away by the tide and lost. The remainder, estimated as representing a sponge of about 13.9 in. in average diameter, and equivalent to a standard cutting estimate of about 140 cuttings, was planted as a first step as nine large fragments only, variable in size, but on the average about fifteen times the cutting standard in volume.

Growth in these fragments through the first period of $9 \frac{1}{2}$ months could not accurately be known, through uncertainty as to the exact proportion of the sponge which they represented. Later, on the same ground, one of them, No. 6037, showed over I9 months, from May 1927 to December 1928, an annual factor of $2 \cdot \mathrm{I}$. In January 1929, another, No. 6040, having an average diameter of 12.25 in., was moved to another ground, where it was divided into four nearly equal quarters, each quarter being planted in a different position as either fifteen or sixteen cuttings. The cuttings were therefore large in size, as against a standard equivalent of 97 for the whole sponge (table, p. 569). Here, in August i930, about I8 months later, four measured cuttings from each of two of these quarter-series - the other two not being measuredshowed through this period an annual growth factor of 2.6 in one and 2.8 in the other; that is to say, at a date 49 months after the first subdivision of the original sponge, which was probably not less than 15 years old when obtained.

\section{BReEding Process In Cuttings}

In the absence of any seriously adverse conditions, no interruption or dislocation of the breeding process, as it would normally take place in the original sponge, should occur in the cutting. The only observed example of 
such interruption occurred among survivors of some 200 cuttings, planted on the Abaco grounds, which suffered great injury from a serious storm in October 1926. The water was driven from the ground where they were planted, and the cuttings were exposed for some hours to the rain. In this case surviving examples of known breeding material either produced no embryos in the following breeding season, or only very few, and none of these, as far as observed, reached complete larval development. In the ordinary course a fragment cut and planted from breeding stock during the breeding season will continue without check and complete the extrusion of its larvae, as in the original sponge; or, if out of the breeding season, it will proceed with the formation of its proportion of the larval brood next to follow, and will liberate them at the proper season. In Fig. I the developing embryos appear as whitish patches distributed over the cut surface.

\section{DURATION OF LIFE}

In other respects, a sponge grown from a cutting becomes a completely independent organism, and may be recut in due course, and repeatedly, for a long period, if not indefinitely. Allusion has already been made (p. 565) to the causes which contribute to the ultimate death of a sponge of natural growth. Under the very different conditions of repeated subdivision the question of age must still be taken into consideration. On this point it can only be stated that if allowance is made for the probable age of the sponges when cuttings were first made, the total age of the material covered by the present records would not exceed 25 years. This, though likely to be much past the period of increasing growth under natural conditions, is probably still far short of the maximum life limit in similar circumstances.

Regarding this question from another aspect, there can be no doubt that in large sponges which have reached their higher limit of growth, the continued production of larvae amounting in some cases to hundreds of thousands annually must contribute to much impoverishment of the parent. So marked is this wastage in the general body tissues, that at the close of the breeding season it is usually distinctly visible to the eye, in the pitted and impoverished appearance of a section through the living sponge.

With the artificial subdivision of any such sponge, its wider distribution, and the proportionately larger food supply made available to the smaller body, a new factor is introduced, enabling the previously arrested body growth to be resumed. Yet in such conditions the larval production of the fragment is not comparable with that of a young sponge of equal or greater volume, which for some 2 years or so from early maturity is very limited. From the time of planting, the larval production of the fragment is approximately that of its corresponding volume in the original stock and similarly to increase with its own growth. 
Whether ultimately this may lead to the death of the parent or not is a question which cannot be solved from the limited records available. In the view of Dr Bidder, whose conclusions on bath sponges are based on past official reports of mine concerning resumption of growth in fragments severed from a fully grown sponge, there is no clear reason to believe that, apart from secondary causes previously referred to (p. 565), any such limitation of life and growth truly and "naturally" exists. With the repeated subdivision of the body of the sponge, in the planting of cuttings, the difficulty of continued self-maintenance beyond the maximum of individual growth is removed, and life should continue indefinitely; nor even should ultimate exhaustion of the parent occur through recurrence of the reproductive process. *

Observations covering about 2000 different sponges, and some 60,000 cuttings derived from them, yield no evidence definitely inconsistent with such a view; that is to say, no distinct example of "senescence" has been observed. From another aspect-and here disregarding partial mortality in the material through external causes, always liable to occur-the total extent of volume increase represented in repeated series of cuttings from a single sponge has, in many experiments, been very far in excess of anything conceivable under conditions of independent growth in that sponge. In the Velvet H. 38 , for example (p. 570), an average annual factor of volume increase of 2.3 would in only 8 years lead to the equivalent of a sponge of about $\mathrm{I} 2.8 \mathrm{ft}$. in average diameter. This would be rather more than four times the average diameter of a very large sponge of the same type, and from the same locality, which I saw several years ago in the warehouse of Messrs Cresswell in London, and probably the largest market sponge on record.

Within the range of the observations, and concerning sponges of a total estimated age not exceeding about 25 years, the recorded evidence seems thus far to support the view that life and growth in sponges of this group has no necessary limit.

I have to express my thanks to the Council of the Marine Biological Association for allowing me the facilities of the Plymouth Laboratory for the preparation of this paper; and to Dr G. P. Bidder for much valuable assistance and advice.

\section{SUMMARY}

An account of the chief earlier experiments, from those of Cavolini in 1785 to the close of Moore's experiments in Florida in 1905, is given and the general subject of reconstruction and growth in the sponge cutting is described in detail.

Under favourable conditions loss of volume in the initial stages, following cutting, should be practically negligible, the early steps in repair and recon-

* Cf. Bidder (r932). Par. I: "water voles, female plaice, sea anemones, and the bath sponge do not show senescence". Par. 3: "Pseudo-senescence and pseudo-specific size are often mere consequences of the decrease in ratio of surface to volume as size increases.... with increase in size the relative diminution in surface requires higher velocity to feed the sponge, lengths of all channels are increased, and consequent friction becomes more than the flagella can overcome." 
struction proceeding without delay after severance of the fragment from the original sponge. As chief among these, the dermal covering required for newly cut surfaces, the closing of most of the exposed apertures of the old canal system, and the retention of one or more of these for future oscula, are accomplished rapidly and, for preliminary purposes, are completed within a very few days.

Pigmentation of new surfaces exposed to the light, though very soon apparent, may require a few weeks for completion. Basal attachment (assuming contact with a fixed basal support) is also soon initiated, but may likewise occupy a few weeks, or several weeks, for purposes of complete natural support. Rotundity-or other prevailing character of form exhibited by the original stock-may be reached in a few months, or in several months, the time varying much with the conditions.

Size of cutting is, for purposes of growth alone, unimportant; the same, or approximately the same, rate of increase occurring in the same sponge under similar conditions, in large fragments or (within limits) in small ones. But, for practical convenience, an optimum size is recommended, equivalent to a sphere of 2.7 in. in average diameter, or a volume of about ro cu. in.

Shortage of food which probably consists chiefly of bacteria may lead to complete suspension of growth, or even to reduction in volume. But in such cases, even after $2 \frac{1}{2}$ years, growth is normally resumed with change to more favourable conditions. Rate of growth amounts, under fair conditions, to an annual factor of volume increase of about $2 \cdot 0$. Under more favourable conditions a factor of 2.5 is frequent, and 3.0 , or a higher rate, may be reached, though less likely to be maintained.

Breeding is in no way interrupted in the cutting, but in all respects proceeds normally as in the sponge from which the cutting was derived.

Recutting of the material at any suitable stage of its growth from plantingand so continuing at intervals, through successive series of planted cuttings grown from the same material-is attended with the same results as in the first planted series, except in so far as certain growth variation may occur with change of surroundings.

The maximum growth attainable is limited by that volume-coupled with its form-capable of self-maintenance as an independent unit by the feeding mechanism of the individual sponge. Beyond this point, death may occur through causes associated with that limitation. Whether, under conditions of repeated cutting and redistribution of the stock, life and growth can be prolonged indefinitely or not, is at present uncertain. Within the extent of the numerous recorded observations, there is no evidence inconsistent with this possibility. 


\section{REFERENCES}

Aristotle, The Works of, I9ro. Translated into English under the Editorship of J. A. Smith, M.A. and W. D. Ross, M.A. Vol. Iv. Historia Animalium. By D'Arcy W. Thompson. Oxford: Clarendon Press.

BIDDER, G. P., I932. Senescence. British Medical fournal, September 24.

Cavolini, F., I785. Memorie per servire alla Storia de' Polipi Marini, pp. 265-72. Napoli.

I853. Memorie postume sceverate dalle schede autografe di...per cura ed a spese di $S$. D(elle) Chiaie, pp. 42-5I. Benevento.

Drew, G. H., I9I4. On the precipitation of calcium carbonate in the sea by marine bacteria, and on the action of denitrifying bacteria in tropical and temperate seas. Carnegie Institution of Washington, Publication, No. 182, pp. 7-45.

MarenZeller, E. von, I878. Die Aufzucht des Badeschwammes aus Theilstücken. Verhandl. der k. k. zool. bot. Ges. Wien, Bd. xxviII, pp. 687-94.

Moore, H. F., I908. A practical method of sponge culture. Bulletin of the Bureau of Fisheries, Vol. xxvIII. Washington. Bureau of Fisheries, Document No. 669. Issued March I9ro.

Rathbun, R., I887. The sponge fishery and trade. U.S. Comm. Fish and Fisheries. The Fisheries and Fishery Industries of the United States. Sect. V. History and Methods of the Fisheries. Vol. II, pp. 8I7-4I. Washington.

Schmidt, O., I862. Die Spongien des adriatischen Meeres. Leipzig. - I864. Supplement der Spongien des adriatischen Meeres. Enthaltend die Histologie und systematische Ergänzungen. Leipzig.

- 1878 . Brehm's Thierleben. Zweite umgearbeitete und vermehrete Auflage. x. Band. Die niederen Thiere. Schwämme. Ordnung 4, pp. 534-5. Leipzig.

Vosmaer, G. C. J., r887. Porifera. Bronn's Die Klassen und Ordnungen des ThierReichs. Leipzig und Heidelberg. 